\title{
Nitric oxide, cholesterol oxides and endothelium-dependent vasodilation in plasma of patients with essential hypertension
}

P. Moriel ${ }^{1}$, A. Sevanian ${ }^{2}$, S. Ajzen ${ }^{3}$, M.T. Zanella ${ }^{3}$,

F.L. Plavnik ${ }^{3}$, H. Rubbo ${ }^{4}$ and D.S.P. Abdalla ${ }^{1}$

\author{
Correspondence \\ D.S.P. Abdalla \\ Faculdade de Ciências Farmacêuticas \\ USP \\ Av. Prof. Lineu Prestes, 580 \\ 05508-900 São Paulo, SP \\ Brasil \\ Fax: 55-11-3813-2197 \\ E-mail: dspa@usp.br
}

Research supported by FAPESP (No. 97/05090-3 to D.S.P. Abdalla, and Doctoral fellowship to P. Moriel) and PRONEX (No. 331/97).

Received March 1, 2002

Accepted August 13, 2002

\author{
1Departamento de Análises Clínicas e Toxicológicas, Faculdade de Ciências \\ Farmacêuticas, Universidade de São Paulo, São Paulo, SP, Brasil \\ ${ }^{2}$ Department of Toxicology, School of Pharmacy, University of Southern California, \\ Los Angeles, CA, USA \\ ${ }^{3}$ Departamentos de Endocrinologia e Nefrologia, Universidade Federal de São Paulo, \\ São Paulo, SP, Brasil \\ ${ }^{4}$ Departamento de Bioquimica, Universidad de la Republica, Montevideo, Uruguay
}

\begin{abstract}
The objective of the present study was to identify disturbances of nitric oxide radical $(\cdot \mathrm{NO})$ metabolism and the formation of cholesterol oxidation products in human essential hypertension. The concentrations of ${ }^{-N O}$ derivatives (nitrite, nitrate, S-nitrosothiols and nitrotyrosine), water and lipid-soluble antioxidants and cholesterol oxides were measured in plasma of 11 patients with mild essential hypertension (H: $57.8 \pm 9.7$ years; blood pressure, $148.3 \pm 24.8 / 90.8 \pm 10.2$ $\mathrm{mmHg}$ ) and in 11 healthy subjects $(\mathrm{N}: 48.4 \pm 7.0$ years; blood pressure, $119.4 \pm 9.4 / 75.0 \pm 8.0 \mathrm{mmHg}$ ). Nitrite, nitrate and S-nitrosothiols were measured by chemiluminescence and nitrotyrosine was determined by ELISA. Antioxidants were determined by reverse-phase HPLC and cholesterol oxides by gas chromatography. Hypertensive patients had reduced endothelium-dependent vasodilation in response to reactive hyperemia (H: 9.3 and N: 15.1\% increase of diameter $90 \mathrm{~s}$ after hyperemia), and lower levels of ascorbate (H: $29.2 \pm 26.0$, N: $54.2 \pm$ $24.9 \mu \mathrm{M})$, urate $(\mathrm{H}: 108.5 \pm 18.9, \mathrm{~N}: 156.4 \pm 26.3 \mu \mathrm{M})$, ß-carotene $(\mathrm{H}$ : $1.1 \pm 0.8, \mathrm{~N}: 2.5 \pm 1.2 \mathrm{nmol} / \mathrm{mg}$ cholesterol), and lycopene (H: $0.4 \pm$ $0.2, \mathrm{~N}: 0.7 \pm 0.2 \mathrm{nmol} / \mathrm{mg}$ cholesterol), in plasma, compared to normotensive subjects. The content of 7-ketocholesterol, $5 \alpha-$ cholestane-3ß,5,6ß-triol and 5,6 $\alpha$-epoxy-5 $\alpha$-cholestan- $3 \alpha$-ol in LDL, and the concentration of endothelin- $1(\mathrm{H}: 0.9 \pm 0.2, \mathrm{~N}: 0.7 \pm 0.1 \mathrm{ng} / \mathrm{ml})$ in plasma were increased in hypertensive patients. No differences were found for ${ }^{\bullet} \mathrm{NO}$ derivatives between groups. These data suggest that an increase in cholesterol oxidation is associated with endothelium dysfunction in essential hypertension and oxidative stress, although ${ }^{-N O}$ metabolite levels in plasma are not modified in the presence of elevated cholesterol oxides.
\end{abstract}

Key words

- Nitrotyrosine

- S-nitrosothiols

- Nitrate

- Oxidized LDL

- Lipid peroxidation

- Endothelin-1 


\section{Introduction}

Endothelial cells release both relaxing and contracting factors which participate in the pathophysiology of essential hypertension. Nitric oxide is a free radical $(\cdot \mathrm{NO})$ that is considered to be the major endotheliumderived relaxing factor, and is released from endothelial cells in response to shear stress or to the stimulation of several receptors on the endothelial cell surface (1). Endothelium-derived contracting factors include endothelin-1, vasoconstrictor prostanoids, angiotensin II and superoxide radical $\left(\mathrm{O}_{2}{ }^{--}\right)$. In patients with essential hypertension, the response to endothelium-dependent agonists is blunted when compared with healthy controls (2). Blockade of cyclooxygenase in hypertensive patients can restore the $\cdot \mathrm{NO}$ production, suggesting that $\cdot \mathrm{NO}$ inactivation may be caused by cyclooxygenase derivatives (3). As $\mathrm{O}_{2}{ }^{--}$is produced by cyclooxygenase (4), and $\bullet \mathrm{NO}$ rapidly reacts with $\mathrm{O}_{2} \cdot-$ to form oxidant and nitrating species $(5,6)$, this $\cdot \mathrm{NO}$ inactivation pathway could be involved in the reduction of endotheliumdependent vasorelaxation found in patients with essential hypertension. Nitrotyrosine has been considered to be an end product of tyrosine nitration induced by peroxynitrite and other nitrating systems (6). Moreover, nitrotyrosine has been detected in human atherosclerotic plaques (7) and in tissues of hypertensive rats (8).

The involvement of lipid peroxidation during the pathogenesis of hypertension has not been extensively studied. Cholesterol oxides (ChOx) are formed as the result of cholesterol oxidation catalyzed by enzymes and by free radical-mediated reactions. $\mathrm{ChOx}$ are toxic to endothelial cells (9) and inhibit -NO production by these cells (10). Oxidized LDL (ox-LDL), containing an increased content of $\mathrm{ChOx}$, reduces the endothelium-dependent relaxation of isolated human internal mammary artery and rat thoracic aorta (11). Accordingly, a number of in vitro and ex vivo animal studies have shown that antioxidants may improve endothelium-dependent vasodilation by limiting lipid peroxidation and improving the bioactivity of $\cdot \mathrm{NO}$ (12).

In hypertension, a disturbance of $\mathrm{O}_{2}{ }^{--}$ and $\cdot \mathrm{NO}$ balance may induce the generation of oxidant and nitrating species, leading to an enhancement of lipid peroxidation and antioxidant consumption in plasma which may result in disturbances of $\cdot \mathrm{NO}$ bioactivity/bioavailability. In order to determine if this free radical imbalance underlies endothelial dysfunction and decreased $\cdot \mathrm{NO}$ bioavailability in essential hypertension, we evaluated flow-mediated endothelium-dependent vasodilation, ${ }^{\circ} \mathrm{NO}$ metabolites and ChOx formation in hypertensive patients.

\section{Material and Methods}

\section{Subjects}

Hypertensive subjects ( $\mathrm{N}=11$; age: 57.8 \pm 9.7 years, male/female: $4 / 7$, blood pressure: $148.3 \pm 24.8 / 90.8 \pm 10.2 \mathrm{mmHg}$ ) were screened at the Kidney Hospital, Federal University of São Paulo (UNIFESP), São Paulo, SP, Brazil. Exclusion criteria included myocardial infarction, unstable angina, smoking, hyperlipidemia, diabetes, significant valvular heart disease, use of antioxidant vitamin supplements, and/or antihypertensive therapy and estrogen replacement therapy. Normotensive subjects $(\mathrm{N}=11$; age: $48.4 \pm 7.0$ years, male/female: $3 / 8$, blood pressure: $119.4 \pm 9.4 / 75.0 \pm 8.0 \mathrm{mmHg}$ ) were normal healthy volunteers with similar exclusion criteria. The study was approved by the Ethics Committee of UNIFESP. All subjects signed written informed consent forms and the study was conducted in accordance to the principles of the Declaration of Helsinki. Blood samples were collected into EDTA-coated tubes and blood plasma was immediately separated by low-speed centrifugation $(1500 \mathrm{~g})$. 
Determination of nitrotyrosine in plasma and LDL

Nitrotyrosine concentration of blood plasma and LDL were determined by ELISA (13). White 96-well plates were coated with $0.5 \mu \mathrm{g} / \mathrm{ml}$ nitro-BSA (100 $\mu \mathrm{l} / \mathrm{well})$ in $0.1 \mathrm{M}$ carbonate-bicarbonate buffer, $\mathrm{pH} 9.4$, overnight at $37^{\circ} \mathrm{C}$. Nitro-BSA was prepared according to a published method (13) and final nitrotyrosine concentration in nitro-BSA was approximately $40-60 \mu \mathrm{M}$. 3-Nitrotyrosine in the proteins of human plasma was determined by a competitive ELISA method (13). After blocking with 5\% nonfat dry milk for 2 $h$ at $37^{\circ} \mathrm{C}$ and washing with Tris-buffered saline (TBS; $50 \mathrm{mM}$ Tris-HCl, $\mathrm{pH}$ 7.4, and $150 \mathrm{mM} \mathrm{NaCl}$ ) containing $0.6 \%$ Tween 20 , the plates were incubated with purified polyclonal anti-nitrotyrosine rabbit IgG (1:1000; $100 \mu \mathrm{l} /$ well) and plasma (1:4 in TBS containing $0.1 \%$ nonfat dry milk) or LDL ( $1 \mathrm{mg}$ of protein $/ \mathrm{ml}$ ), previously separated by gradient ultracentrifugation for $2 \mathrm{~h}$ at $37^{\circ} \mathrm{C}$. The nitro-BSA standard curve was obtained by incubating serial dilutions of nitro-BSA (60 $\mathrm{nM}$ to $0.15 \mathrm{nM}$; 10 points) in TBS containing $0.1 \%$ nonfat dry milk ( $100 \mu \mathrm{l} /$ well $)$. Next, the plates were washed and incubated with mouse anti-rabbit IgG peroxidase conjugate $(1: 5000 ; 100 \mu \mathrm{l} /$ well $)$ for $1 \mathrm{~h}$ at $37^{\circ} \mathrm{C}$, followed by the addition of $2.3 \mathrm{mM}$ luminol, $0.9 \mathrm{mM}$ p-iodophenol (200 $\mu \mathrm{l} / \mathrm{well})$, and 3.9 $\mathrm{nM}$ hydrogen peroxide $(50 \mu \mathrm{l} /$ well $)$. The chemiluminescence intensity was determined immediately using a microplate reader (LumiCount, Packard, Meriden, CT, USA). The concentrations of free and protein-bound nitrotyrosine that inhibit anti-nitrotyrosine antibody binding were estimated from the standard curves and were reported as nitro-BSA equivalents, i.e., an equivalent concentration of 3nitrotyrosine in nitro-BSA that produces the equivalent inhibition as the nitrated proteins (14). All samples and standard curves were run in triplicate. Controls were performed by preincubating the nitrated proteins with 10
mM sodium dithionite. Data for standard curves were fitted to a logistic plot using the Origin software. The nitro-BSA equivalents of plasma samples were calculated by the logit plot on the $y$-axis $\left(\operatorname{logit}\left(\mathrm{B} / \mathrm{B}_{0}\right)=\log _{\mathrm{e}}\left[\mathrm{B} / \mathrm{B}_{0}\right] /[\mathrm{B}-\mathrm{B} /\right.$ $\left.\mathrm{B}_{0}\right]$ and $\log$ concentration on the $\mathrm{x}$-axis.

\section{Determination of nitrite, nitrate and S-nitrosothiols}

The concentration of nitrate in blood plasma was determined by chemiluminescence, elicited by the reaction of ${ }^{\bullet} \mathrm{NO}$ with ozone after nitrate reduction with $\mathrm{VCl}_{3}$ saturated solution in $1 \mathrm{M} \mathrm{HCl}$, at $90^{\circ} \mathrm{C}$, using an ${ }^{\circ} \mathrm{NO}$ analyzer $\left(\mathrm{NOA}^{\mathrm{TM} 280}\right.$, Sievers Instruments Inc., Boulder, CO, USA). Nitrite was determined after reduction with $1 \% \mathrm{KI}$ solution in glacial acetic acid to convert nitrite to ${ }^{\circ}$ NO. Samples used to determine S-nitrosothiols were analyzed either without pretreatment or after preincubation for $5 \mathrm{~min}$ at room temperature with a molar excess of $\mathrm{HgCl}_{2}$ from a saturated aqueous solution, by the method of Ewing and Janero (15). Samples containing $5 \mathrm{ml}$ 1\% KI solution in glacial acetic acid were injected into the $\mathrm{NO}$ analyzer according to the manufacturer's recommendations. For total Snitrosothiol quantification, the difference between the sample response after $\mathrm{HgCl}_{2}$ treatment and without pretreatment was taken to be the amount of S-nitrosothiol-bound ${ }^{*} \mathrm{NO}$.

\section{Determination of cholesterol and triglycerides}

The concentrations of total cholesterol, triglyceride and high density lipoprotein (HDL)cholesterol were determined by enzymatic analyses using commercial kits (Biosystem, Barcelona, Spain). LDL-cholesterol was calculated by the Friedewald equation.

\section{Determination of cholesterol oxides in LDL}

LDL was isolated by sequential ultracentrifugation and $\mathrm{ChOx}$ content was determined 
by the method described by Hodis el al. (16). The lipids were extracted with methanol: chloroform (1:2) and applied to Diol solidphase extraction columns (Waters, São Paulo, $\mathrm{SP}$, Brazil). The cholesterol/ChOx were collected, hydrolyzed by cold alkaline saponification, derivatized with N,O-bis (trimethylsilyl) trifluoroacetamide(BSTFA-Merck, São Paulo, SP, Brazil), and analyzed by gas chromatography. Gas chromatography was performed using a Hewlett Packard 6890 plus fitted with a HP-5 capillary column ( $30 \mathrm{~m} \times 0.32 \mathrm{~mm}$ ID, $0.25 \mu \mathrm{m}$ film thickness - $5 \%$ phenylsiloxane, Hewlett Packard, Hopkins, MN, USA) and hydrogen as carrier gas.

\section{Determination of antioxidants}

The concentration of $\alpha$-tocopherol, $\beta$-carotene, lycopene (17), ascorbate and urate (18) in blood plasma were determined by HPLC using a C-18 ODS column (Shimadzu Corp., Tokyo, Japan).

\section{Determination of plasma endothelin-1}

The content of endothelin-1 in blood plasma was determined by ELISA with a commercially available reagent kit (EIAH 6901 - endothelin-1, Peninsula Laboratories, Inc., Oxford, England).

\section{Evaluation of endothelium-dependent vasodilatation}

Flow-mediated endothelium-dependent

Figure 1. Flow-mediated endothelium-dependent vasodilation in response to reactive hyperemia. Vasodilation was determined in the brachial artery at 10 and $90 \mathrm{~s}$ after cuff deflation. Results are reported as means \pm SEM of percent increase of diameter. $N=11 .{ }^{*} P<0.05$ compared to normotensive subjects (Tukey test).

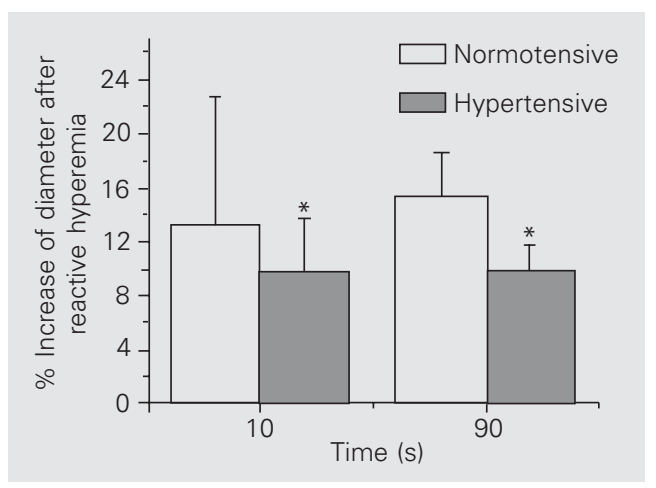

vasodilatation of the brachial artery was determined noninvasively with vascular ultrasound as previously described (19). Hyperemia was induced by a cuff that was inflated on the proximal portion of the upper arm to occlude arterial flow $(>200 \mathrm{mmHg})$ for 5 min and rapidly deflated. Ultrasound images of the brachial artery were obtained at baseline and at 15 and $90 \mathrm{~s}$ after deflation. The brachial artery was then allowed to return to baseline level. Then, isosorbide dinitrate was given sublingually, and the brachial artery was imaged after $5 \mathrm{~min}$. The response to isosorbide dinitrate is a measure of endothelium-independent vasodilatation. Intimamedia thickness was determined in the carotid and brachial arteries by ultrasound (ATL, HDI-Ultramark-9).

\section{Statistical analysis}

Data are reported as means \pm SEM. Statistical analysis was performed by the Tukey test as a post-test after ANOVA, with $\mathrm{P}<0.05$ considered to be significant. Correlations were calculated by the Spearman test (Sigma Stat software).

\section{Results}

Flow-mediated endothelium-dependent vasodilatation in response to hyperemia was $61.1 \%$ lower in essential hypertensive patients (Figure 1); in contrast, the vasodilating effect of sodium nitroprusside was similar in normotensive subjects and hypertensive patients (results not shown). No difference was found in the intima-medial thickness between the groups studied (normal: carotid $0.66 \pm 0.08 \mathrm{~mm}$, brachial $0.39 \pm 0.19 \mathrm{~mm}$; hypertensive: carotid $0.75 \pm 0.10 \mathrm{~mm}$, brachial $0.36 \pm 0.08 \mathrm{~mm}$ ). These findings suggest impaired endothelial vasodilation in the essential hypertensive subjects. The lack of difference between the two groups in relation to the levels of nitrotyrosine, nitrite, nitrate and S-nitrosothiols (Table 1) sug- 
gests that ${ }^{\circ} \mathrm{NO}$ production is not decreased in essential hypertension. The normal concentrations of cholesterol and triglycerides found in hypertensive patients confirmed that they had no associated hyperlipidemia (Table 1). The increase of endothelin-1 in blood plasma of hypertensive patients (Table 1) indicates the importance of this contracting factor in essential hypertension. The increased lipid peroxidation in this situation is shown by the higher content of 7-ketocholesterol $(62 \%$ higher in hypertensive than in normal subjects), $5 \alpha$-cholestane-3ß,5,6ß-triol ketocholesterol ( $80 \%$ higher in hypertensive than

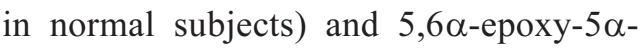
cholestan-3 $\alpha$-ol $(50 \%$ higher in hypertensive than in normal subjects) in LDL particles of hypertensive patients than in those of normotensive subjects (Figure 2). The increase of antioxidant consumption is indicated by the lower concentrations of $\beta$-carotene, lycopene, ascorbate and urate in hypertensive patients (Table 2). Correlation analysis showed that the flow-mediated endothelium-dependent vasodilation was negatively correlated with total cholesterol $(r=0.32$, $\mathrm{P}=0.04$ ) and positively correlated with $\alpha$ tocopherol $(\mathrm{r}=0.67, \mathrm{P}<0.01)$, ascorbate $(\mathrm{r}=$ $0.44, \mathrm{P}=0.02)$ and urate $(\mathrm{r}=0.41, \mathrm{P}=0.04)$.

\section{Discussion}

The present investigation showed reduced flow-mediated endothelium-dependent vasodilation associated with increased levels of LDL-cholesterol oxides and plasma endothelin-1. This was accompanied by a decrease in lipid- and water-soluble antioxidants in blood plasma of untreated patients with borderline essential hypertension. Several mechanisms implicating the action of ox-LDL have been proposed to account for the impairment of endothelium-dependent vasodilation, such as i) reduced synthesis of -NO by endothelium in response to inhibition of $\cdot \mathrm{NO}$ synthase (NOS) (20), ii) $\cdot \mathrm{NO}$ inactivation as a result of the increased pro-
Table 1. Lipids, endothelin-1, nitrotyrosine and nitric oxide derivatives in plasma of patients with essential hypertension and normotensive subjects.

\begin{tabular}{lrr}
\hline Analyte & $\begin{array}{r}\text { Normotensive } \\
(\mathrm{N}=11)\end{array}$ & $\begin{array}{r}\text { Essential hypertensive } \\
(\mathrm{N}=11)\end{array}$ \\
\hline Cholesterol (mg/dl) & $166.7 \pm 23.7$ & $178.4 \pm 11.4$ \\
VLDL-cholesterol (mg/dl) & $24.2 \pm 14.6$ & $23.3 \pm 12.5$ \\
LDL-cholesterol (mg/dl) & $104.5 \pm 35.3$ & $111.5 \pm 17.0$ \\
HDL-cholesterol (mg/dl) & $38.8 \pm 12.4$ & $40.3 \pm 15.7$ \\
Plasma nitrotyrosine (nitro ALB & $40.2 \pm 2.0$ & $44.4 \pm 2.2$ \\
$\quad$ equivalents) (nM) & $19.5 \pm 6.9$ & $18.6 \pm 8.0$ \\
LDL nitrotyrosine (nitro ALB & & \\
$\quad$ equivalents) (nM) & $20.7 \pm 16.0$ & $18.3 \pm 10.7$ \\
Nitrate $(\mu M)$ & $1.0 \pm 0.5$ & $1.0 \pm 0.5$ \\
Nitrite $(\mu M)$ & $0.3 \pm 0.2$ & $0.3 \pm 0.2$ \\
S-nitrosothiols $(\mu M)$ & $0.7 \pm 0.1$ & $0.9 \pm 0.2^{*}$ \\
Endothelin-1 (ng/ml) & &
\end{tabular}

Data are reported as means \pm SEM. ${ }^{*} \mathrm{P}<0.05$ compared to normotensive subjects (Tukey test).

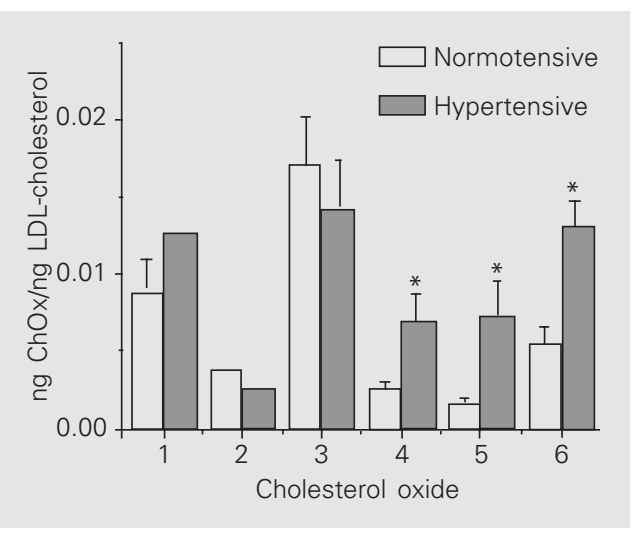

Figure 2. Cholesterol oxides (ChOx) in LDL of normotensive subjects and essential hypertensive patients. $1,7 \alpha-\mathrm{OH}$, cholest-5-ene-3ß, 7 $\alpha$-diol; 2, 7ß$\mathrm{OH}$, cholest-5-ene-3ß,7ß-diol; 3 , cholesteryl-ß-epoxide, cholestan-5ß, 6ß-epoxy-3ß-ol; 4, cholesteryl- $\alpha$-epoxide, choles$\tan -5 \alpha, 6 \alpha$-epoxy-3ß-ol; 5, cho-

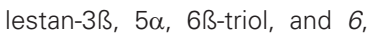
7-ketocholesterol. Results are reported as means \pm SEM $\mathrm{N}=11 .{ }^{*} \mathrm{P}<0.05$ compared to the normotensive group (Tukey test).

Table 2. Antioxidants in plasma of patients with essential hypertension and normotensive subjects.

\begin{tabular}{lrr}
\hline Analyte & $\begin{array}{c}\text { Normotensive } \\
(\mathrm{N}=11)\end{array}$ & $\begin{array}{c}\text { Essential hypertensive } \\
(\mathrm{N}=11)\end{array}$ \\
\hline Ascorbate $(\mu \mathrm{M})$ & $54.2 \pm 24.9$ & $29.2 \pm 26.0^{*}$ \\
Urate $(\mu \mathrm{M})$ & $156.4 \pm 26.3$ & $108.5 \pm 18.9^{*}$ \\
$\alpha$-Tocopherol $(\mathrm{nmol} / \mathrm{mg}$ cholesterol) & $23.9 \pm 4.4$ & $19.6 \pm 5.6$ \\
B-Carotene $(\mathrm{nmol} / \mathrm{mg}$ cholesterol) & $2.5 \pm 1.2$ & $1.1 \pm 0.8^{*}$ \\
Lycopene $(\mathrm{nmol} / \mathrm{mg}$ cholesterol) & $0.7 \pm 0.2$ & $0.4 \pm 0.2^{*}$ \\
\hline
\end{tabular}

Data are reported as means \pm SEM. ${ }^{*} \mathrm{P}<0.05$ compared to normotensive subjects (Tukey test). 
duction of $\mathrm{O}_{2}{ }^{--}$resulting in peroxynitrite $\left(\mathrm{ONOO}^{-}\right)(21)$, iii) increased synthesis of endothelin-1 (14), iv) inhibition of $\mathrm{PGI}_{2}$ release by endothelial cells (22), and v) selective inhibition of vascular smooth muscle cell relaxation in rabbit and human arteries (23). Moreover, ox-LDL potentiates the contractile response of blood vessels to contractile agonists (11). Thus, ox-LDL not only appears to inhibit the ability of blood vessels to relax, but renders vessels more prone to vasospasm in response to contractile stimuli (11).

Among the components of ox-LDL, ChOx are potent inhibitors of endothelium-dependent relaxation in rabbit aortic segments (24). Moreover, induction of hypertension by coarctation of the aorta in rabbits resulted in a marked enhancement of $\mathrm{ChOx}$ in plasma and aortic tissue (16). ChOx may be some of the agents responsible for vascular injury or inhibition of ${ }^{\circ} \mathrm{NO}$ production by the vascular endothelium. Cholesterol derivatives oxidized at position 7, particularly 7-ketocholesterol and 7ß-hydroxycholesterol, can significantly reduce the histamine-induced release of $\mathrm{NO}$ from human umbilical vein endothelial cells (10). It has been suggested that 7-ketocholesterol does not reduce ${ }^{\circ} \mathrm{NO}$ release by altering the $\mathrm{Ca}^{2+}$-dependent NOS activation steps, but rather by changing the physicochemical properties of membranes (10). A characteristic of endothelial NOS is to be targeted to signal-transducing membrane microdomains called plasmalemmal caveolae. Membrane cholesterol is essential for their normal function and oxidation of cholesterol at position 7 may alter endothelial ${ }^{\circ} \mathrm{NO}$ production through direct effects on caveolae (24). However, our data for hypertensive patients did not indicate any effect on ${ }^{-N O}$ production. Although 7-ketocholesterol was increased in the LDL of these hypertensive patients, the values of $\cdot \mathrm{NO}$ metabolites measured in plasma, i.e., nitrite, nitrate and S-nitrosothiols, were similar to those of normotensive subjects. 7-Ketocho- lesterol and possibly other components of ox-LDL have been reported to be assimilated into glycosphingolipid-rich membranes (associated with caveolae) and increase the activity of src kinases, possibly by interacting with caveolin (25). However, the increases in plasma 7-ketocholesterol reported in humans may be insufficient to affect NOS association with caveolae and $\mathrm{NO}$ production as found in cell culture.

It is known that in aqueous media, such as blood plasma, ${ }^{\circ} \mathrm{NO}$ reacts with oxygen to yield nitrite $\left(\mathrm{NO}_{2}^{-}\right)$, which is rapidly oxidized to nitrate $\left(\mathrm{NO}_{3}{ }^{-}\right)$(26). Moreover, peroxynitrite may undergo isomerization to form nitrate (27). ${ }^{\circ} \mathrm{NO}$ may also be converted to the nitrosonium cation through interaction with oxygen and thiol compounds (RSH; 28). S-nitrosothiols (RSNOs) are considered to be ${ }^{\circ} \mathrm{NO}$ pools, buffering the level of ${ }^{\bullet} \mathrm{NO}$, which is important for ${ }^{\circ} \mathrm{NO}$ storage and transport. Thus, these $\mathrm{NO}$ metabolites should reflect the overall $\cdot \mathrm{NO}$ production in the organism. One possible interpretation of our data is that ${ }^{\circ} \mathrm{NO}$ release may be decreased only in the microenvironment of the abluminal side of the endothelium at some points of the vasculature causing impairment of endothelium-dependent vasodilation without affecting ${ }^{\circ} \mathrm{NO}$ luminal release or the circulating pool of ${ }^{\bullet} \mathrm{NO}$ metabolites. In contrast to the lack of effect on ${ }^{*} \mathrm{NO}$ metabolites, the ChOx-enriched LDL particles may act on endothelial cells enhancing endothelin-1 release, which is a vasoconstrictive molecule. In fact, we found increased concentrations of endothelin-1 in plasma of essential hypertensive patients. Our data agree with in vitro studies showing that ox-LDL increases the release of endothelin-1 by endothelial cells (14) or its activity on target vascular cells. Indeed, ChOx have been shown to alter the localization and activity of the endothelin receptor by switching its internalization via caveolae to clathrin-coated pits (29). It was recently reported that the binding of activated platelets to the lectin- 
like ox-LDL receptor-1 (LOX-1) enhanced the release of endothelin-1 from endothelial cells (30). As LOX-1 is upregulated in vivo in the presence of hypertension (31), oxLDL could modulate endothelin-1 release through binding to LOX-1 in endothelial cells. Although the ox-LDL components responsible for mediating endothelin-1 release were not defined, $\mathrm{ChOx}$ are potential candidates. This may be important for the pathophysiology of essential hypertension and deserves further studies.

The in vivo formation or origin of $\mathrm{ChOx}$ is not completely understood. In vitro studies have shown that oxidation of cholesterol in LDL occurs as a secondary event to lipid peroxidation via the attack of fatty acid peroxyl/alkoxyl radicals at the 7-position of cholesterol (32). LDL oxidation by peroxynitrite leads to similar cholesterol oxidation (32). The main oxysterols formed were 5,6 ß-epoxycholesterol, 7-ketocholesterol, 7ßhydroxycholesterol, $7 \alpha$-hydroxycholesterol, and 5,6 $\alpha$-epoxycholesterol (32). It is interesting to note that in blood plasma (Figure 2) the concentration of 5,6 ß-epoxycholesterol is higher than that of 7-ketocholesterol, which suggests that peroxynitrite may be one of the oxidant species leading to in vivo free radical-mediated cholesterol oxidation. Patel et al. (32) showed that no formation of $5 \alpha-$ cholestane-3B,5,6ß-triol or the 24-,25-27hydroxycholesterols was detected in LDL oxidized in vitro. However, in the plasma of hypertensive patients studied here we found increased levels of 7-ketocholesterol, 5,6 $\alpha$ epoxycholesterol and $5 \alpha$-cholestane-3ß,5,6ßtriol. This profile is similar to that found in hypertensive rabbits (16) and suggests that additional mechanisms are contributing to in vivo cholesterol oxidation.

The decreased superoxide dismutase activity in blood plasma described for hypertensive patients (33) would favor the reaction of ${ }^{\bullet} \mathrm{NO}$ with $\mathrm{O}_{2}{ }^{--}$resulting in peroxynitrite, or ${ }^{\bullet} \mathrm{NO}_{2}$ plus $\mathrm{CO}_{3}{ }^{\cdot-}$, which would lead to lipid peroxidation and nitration of pro- teins. Pulse radiolysis studies have shown that the highest nitration yield is obtained for similar fluxes of $\mathrm{O}_{2}{ }^{\cdot-}$ and $\cdot \mathrm{NO}$ (34). Under physiological conditions, ${ }^{\bullet} \mathrm{NO}\left(0.1-3.0 \times 10^{-9}\right.$ $\mathrm{M})$ exceeds the estimated concentration of $\mathrm{O}_{2} \cdot-\left(10^{-9}-10^{-12} \mathrm{M}\right)$, resulting in a high $\cdot \mathrm{NO} /$ $\mathrm{O}_{2}{ }^{--}$ratio in the vessel wall (35). In this context, the effect of angiotensin II on endothelium is particularly important during hypertension. It is known that angiotensin II increases systemic ${ }^{\circ O}$ production and induces the production of $\mathrm{O}_{2}{ }^{--}$through $\mathrm{AT}_{1}$ receptor-dependent activation of the $\mathrm{NAD}(\mathrm{P}) \mathrm{H}$ oxidase in endothelial cells (36). Moreover, chronic $\mathrm{AT}_{1}$ blockade or angiotensin-converting enzyme inhibition prevents the development of NOS inhibitor-induced hypertension and reverses it by restoring -NO bioavailability and the endotheliumdependent vasodilation (37). Although decreased scavenging of $\mathrm{O}_{2}{ }^{--}$by superoxide dismutase and increased destruction of ${ }^{\circ} \mathrm{NO}$ have been implicated in hypertension (38), in the present study the nitrotyrosine levels were not increased in plasma or LDL of patients with essential hypertension. This could be explained by the diffusion of peroxynitrite from the lumen of blood vessels to the interior of blood cells. It is known that peroxynitrite produced by the endothelium, even in the presence of $\mathrm{CO}_{2}$, can diffuse and penetrate the erythrocytes (39), possibly leading to the oxidation and/or nitration of the protein and non-protein components of hemoglobin. This diffusional property of peroxynitrite could explain the comparable plasma levels of nitrotyrosine observed in both normal and hypertensive patients. Thus, the concentration of free and protein-associated nitrotyrosine in blood plasma is the net product of the generation rate by intra- and extracellular nitrating pathways.

In the present study, the flow-mediated endothelium-dependent vasodilation was positively correlated with the levels of $\alpha$ tocopherol, ascorbate, and urate in essential hypertensive patients. Additionally, the con- 
centrations of ascorbate, urate, ß-carotene, and lycopene were lower in these patients in comparison to normotensive subjects. Antioxidants have positive effects in preserving the biological activity of endotheliumderived $\cdot$ NO (12). Supplementation studies have shown that ascorbate improves endothelial dysfunction in patients with essential hypertension (40). Moreover, in vitro studies have shown that ascorbate increases the production of citrulline, the byproduct of -NO synthesis, and cyclic GMP, a marker of -NO bioactivity (12). Ascorbate may also regenerate $\alpha$-tocopherol from its tocopheroxyl radical and sparing glutathione, which could contribute to enhancing the formation of S-nitrosothiols (12). It is suggested that $\alpha$ tocopherol acts on the vascular wall by inhibiting protein kinase $\mathrm{C}$ activation by oxLDL, hence decreasing superoxide production (12). Both ascorbate and $\alpha$-tocopherol can reduce in vivo or ex vivo markers of lipoprotein oxidation (12). Additionally, treatment of hypertensive rabbits with the antioxidant probucol reduced the increase of ChOx content in plasma and aortic tissue (16). Thus, the decrease of antioxidants could contribute to the impairment of endothelium-dependent vasodilation either by direct effects on endothelium or by inhibiting the generation of oxidized lipids, including ChOx.

We have shown that individuals with essential hypertension had reduced endothelium-dependent vasodilation, in parallel to increased ChOx levels and endothelin-1. These increases are known to be associated with oxidant stress and to be enhanced by the decrease in plasma antioxidants, without alterations of $\cdot \mathrm{NO}$-derived metabolites. To our knowledge, ours is the first study to show an increased formation of $\mathrm{ChOx}$ in hypertensive humans, suggesting that $\mathrm{ChOx}$ may play a role in the endothelial dysfunction found in essential hypertension.

\section{References}

1. Burnstock G (1999). Release of vasoactive substances from endothelial cells by shear stress and purinergic mechanosensory transduction. Journal of Anatomy, 94: 335-342.

2. Cardillo C, Kilcoyne CM, Quyyumi AA, Cannon 3rd RO \& Panza JA (1998). Selective defect in nitric oxide synthesis may explain the impaired endothelium-dependent vasodilatation in patients with essential hypertension. Circulation, 97: 851856.

3. Pagano PJ, Lin L, Sessa WC \& Nasjletti A (1991). Arachidonic acid elicits endothelium-dependent release from rabbit aorta of a constrictor prostanoid resembling prostaglandin endoperoxides. Circulation Research, 69: 396-405.

4. Taedieu D, Jaeg JP, Deloly A, Corpet DE \& Petit CR (2000). The COX-2 inhibitor nimesulide suppresses superoxide and 8hydroxydeoxyguanosine formation, and stimulates apoptosis in mucosa during early colonic inflammation in rats. Carcinogenesis, 21: 973-976.

5. Beckman JS, Beckman TW, Chen JC, Marshall PA \& Freeman BA (1990). Apparent hydroxyl radical production by peroxy- nitrite: Implications of endothelial injury from nitric oxide and superoxide. Proceedings of the National Academy of Sciences, USA, 87: 1620-1624.

6. Halliwell B (1997). What nitrates tyrosine? Is nitrotyrosine specific as a biomarker of peroxynitrite formation in vivo? FEBS Letters, 411: 157-160.

7. Beckman JS, Ye YZ, Anderson PG, Chen J, Accavitti MA, Tarpey MM \& White CR (1994). Extensive nitration of protein tyrosines in human atherosclerosis detected by immunohistochemistry. Biological Chemistry Hoppe-Seyler, 375: 81-88.

8. Roberts CK, Vaziri ND, Wang XO \& Barnard RJ (2000). Enhanced NO inactivation and hypertension induced by a highfat, refined-carbohydrate diet. Hypertension, 36: 423-429.

9. Zhou Q, Wasowicz E, Handler B, Fleischer $L$ \& Kummerow FA (2000). An excess concentration of oxysterols in the plasma is cytotoxic to cultured endothelial cells. Atherosclerosis, 149: 191-197.

10. Deckert V, Brunet A, Lantoine F, Lizard G, Millanvoye-van Brussel E, Monier S, Lagrost L, David-Dufilho M, Gambert P \& Devynck MA (1998). Inhibition by choles- terol oxides of NO release from human vascular endothelial cells. Arteriosclerosis, Thrombosis, and Vascular Biology, 18: 1054-1060.

11. Mougenot N, Lesnik P, Ramirez-Gil JF Nataf P, Diczfalusy U, Chapman MJ \& Lechat P (1997). Effect of the oxidation state of LDL on the modulation of arterial vasomotor response in vitro. Atherosclerosis, 133: 183-192.

12. Carr A \& Frei B (2000). The role of natura antioxidants in preserving the biological activity of endothelium-derived nitric oxide. Free Radical Biology and Medicine, 28: 1806-1814

13. Moriel P, Pereira IR, Bertolami MC \& Abdalla DS (2001). Is ceruloplasmin an important catalyst for S-nitrosothiol generation in hypercholesterolemia? Free Radical Biology and Medicine, 30: 318326.

14. Boulanger CM, Tanner FC, Bea ML, Hahn AW, Werner A \& Luscher TF (1992). Oxidized low density lipoproteins induce mRNA expression and release of endothelin form human and porcine endothelium. Circulation Research, 70: 1191-1197.

15. Ewing JF \& Janero DR (1998). Specific 
S-nitrosothiol (thionitrite) quantification as solution nitrite after vanadium (III) reduction and ozone-chemiluminescent detection. Free Radical Biology and Medicine, 25: 621-628.

16. Hodis HN, Hashimoto S, Mack WJ \& Sevanian A (2000). Probucol reduces oxysterol formation in hypertensive rabbits. Hypertension, 36: 436-441.

17. Thurnham DI, Smith E \& Flora PS (1988). Concurrent liquid-chromatographic assay of retinol, alpha-tocopherol, beta-carotene, alpha-carotene, lycopene, and betacryptoxanthin in plasma, with tocopherol acetate as internal standard. Clinical Chemistry, 34: 377-381.

18. Pachla LA \& Kissinger PT (1979). Analysis of ascorbic acid by liquid chromatography with amperometric detection. Methods in Enzymology, 62: 15-24.

19. Takase B, Uehata A, Akima T, Nagai T, Nishioka T, Hamabe A, Satomura K, Ohsuzu F \& Kurita A (1998). Endotheliumdependent flow-mediated vasodilation in coronary and brachial arteries in suspected coronary artery disease. American Journal of Cardiology, 82: 1535-1539.

20. Liao JK, Shin WS, Lee WY \& Clark SL (1995). Oxidized low-density lipoprotein decreases the expression of endothelial nitric oxide synthase. Journal of Biological Chemistry, 270: 319-324.

21. Vergnani $L$, Hatrik S, Ricci F, Passaro A, Manzoli N, Zuliani G, Brovkovych V, Fellin $R$ \& Malinski T (2000). Effect of native and oxidized low-density lipoprotein on endothelial nitric oxide and superoxide production: key role of L-arginine availability. Circulation, 101: 1261-1266.

22. Dart AM \& Chin-Dusting JP (1999). Lipids and the endothelium. Cardiovascular Research, 43: 308-322.

23. Cox DA \& Cohen ML (1996). Effects of oxidized low-density lipoprotein on vascular contraction and relaxation: clinical and pharmacological implications in atherosclerosis. Pharmacological Reviews, 48: 3-19.

24. Deckert V, Persegol L, Viens L, Lizard G, Athias A, Lallemant C, Gambert P \& Lagrost L (1997). Inhibitors of arterial relaxation among components of human oxidized low-density lipoproteins. Cholesterol derivatives oxidized in position 7 are potent inhibitors of endothelium-dependent relaxation. Circulation, 95: 723-731.

25. Myers SJ \& Stanley KK (1999). Src family kinase activation in glycosphingolipid-rich membrane domains of endothelial cells treated with oxidised low density lipoprotein. Atherosclerosis, 143: 389-397.

26. Wink DA, Cook JA, Pacelli R, Liebman J, Krishna MC \& Mitchel JB (1995). Nitric oxide (NO) protects against cellular damage by reactive oxygen species. Toxicology Letters, 82/83: 221-226.

27. Misko TP, Highkin MK, Veenhuizen AW, Manning PT, Stern MK, Currie MG \& Salvemini D (1998). Characterization of the cytoprotective action of peroxynitrite decomposition catalysts. Journal of Biological Chemistry, 273: 15646-15653.

28. Gow AJ, Buerk DG \& Ischiropoulos HA (1997). Novel reaction mechanism for the formation of S-nitrosothiol in vivo. Journal of Biological Chemistry, 272: 2841-2845.

29. Okamoto $Y$, Ninomiya H, Miwa S \& Masaki T (2000). Cholesterol oxidation switches the internalization pathway of endothelin receptor type A from caveolae to clathrin-coated pits in Chinese hamster ovary cells. Journal of Biological Chemistry, 275: 6439-6446.

30. Kakutani M, Masaki $T$ \& Sawamura $T$ (2000). A platelet-endothelium interaction mediated by lectin-like oxidized low-density lipoprotein receptor-1. Proceedings of the National Academy of Sciences, USA, 97: 360-364.

31. Nagase M, Hirose $S$, Sawamura T, Masaki
T \& Fujita T (1997). Enhanced expression of endothelial oxidized low-density lipoprotein receptor (LOX-1) in hypertensive rats. Biochemical and Biophysical Research Communications, 237: 496-498.

32. Patel RP, Diczfalusy U, Dzeletovic S, Wilson MT \& Darley-Usmar VM (1996). Formation of oxysterols during oxidation of low density lipoprotein by peroxynitrite, myoglobin, and copper. Journal of Lipid Research, 37: 2361-2371.

33. Kumar KV \& Das UN (1993). Are free radicals involved in the pathobiology of human essential hypertension? Free Radical Research Communications, 19: 59-66.

34. Goldstein S, Czapski G, Lind J \& Merényi $G$ (2000). Tyrosine nitration by simultaneous generation of ${ }^{*} \mathrm{NO}$ and $\mathrm{O}_{2}{ }^{*-}$ under physiological conditions. Journal of Biological Chemistry, 275: 3031-3036.

35. Wever R, Stroes E \& Rabelink TJ (1998). Nitric oxide and hypercholesterolemia: a matter of oxidation and reduction? Atherosclerosis, 137: S51-S60.

36. Nava E, Rodriguez F, Moreno C, Llinas MT \& Salazar FJ (2000). Release of nitric oxide after acute hypertension. Journal of Cardiovascular Pharmacology, 36: 444450.

37. Zatz R \& Baylis C (1998). Chronic nitric oxide inhibition model six years on. Hypertension, 32: 958-964.

38. McIntyre M, Bohr DF \& Dominiczak AF (1999). Endothelial function in hypertension: the role of superoxide anion. Hypertension, 34: 539-545.

39. Romero N, Denicola A, Souza JM \& Radi $R$ (1999). Diffusion of peroxynitrite in the presence of carbon dioxide. Archives of Biochemistry and Biophysics, 368: 23-30.

40. Solzbach $U$, Hornig $B$, Jeserich $M$ \& Just $H$ (1997). Vitamin C improves endothelial dysfunction of epicardial coronary arteries in hypertensive patients. Circulation, 96: 1513-1519. 